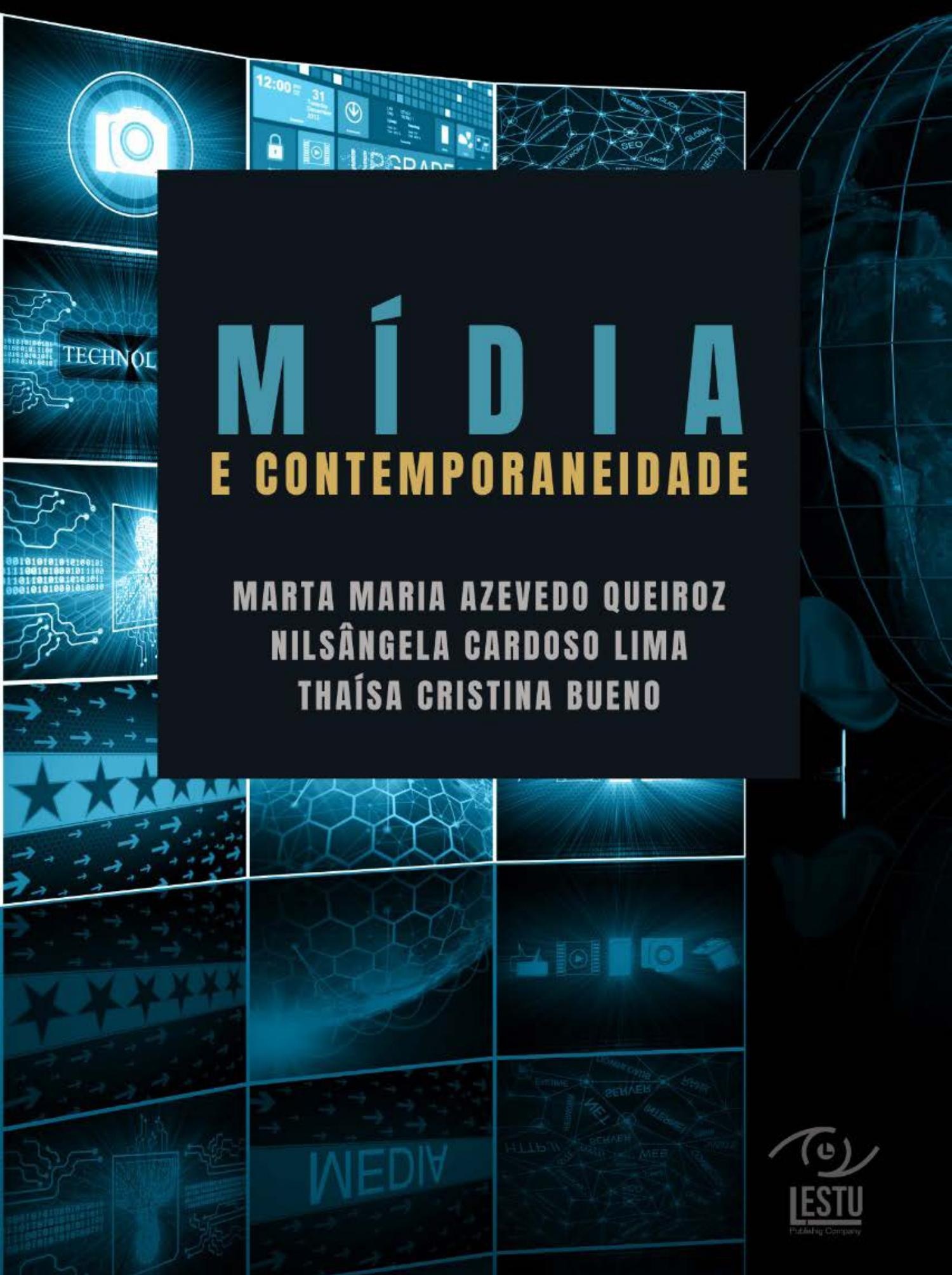




\section{Expediente}

Direção Editorial: Edson Rodrigues Cavalcante Projeto Gráfico: Ana Kelma Gallas

Diagramação: Kleber Albuquerque Filho

TI Publicações OMP Books: Eliezyo Silva

Apoio Editorial: Jader de Oliveira

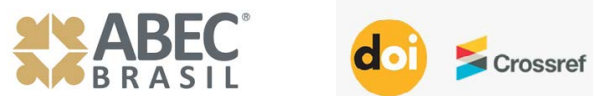

FICHA CATALOGRÁFICA

Dados Internacionais de Catalogação na Publicação (CIP)

(Câmara Brasileira do Livro, SP, Brasil)

Q3m

QUEIROZ, Marta Maria Azevedo; LIMA, Nilsângela Cardoso; BUENO, Thaisa Cristina.

Mídia e Contemporaneidade: estudos transdisciplinares / Marta Maria Azevedo Queiroz, Nilsângela Cardoso Lima e Thaisa Cristina Bueno. (Orgs.). São Paulo: Lestu Publishing Company, 2022.

272 p. online. pdf.

ISBN: 978-65-996314-5-0

DOI: 10.51205/lestu.978-65-996314-5-0

1. Mídia. 2. Contemporaneidade. 3. Jornalismo. 4. Ciências da Comunicação. 5. Sociedade Midiatizada. I. Autor(a). II. Título. III. Editora.

CDD: 070.

Índices para catálogo sistemático:

1. Jornalismo: Mídia. Sociedade Midiatizada. Comunicação.

\section{(0) \\ IESTU}

A Lestu Publishing Company é uma editora que acredita na Ciência Aberta. Permitimos a leitura, download e/ou compartilhamento do conteúdo desta obra para qualquer meio ou formato, desde que os textos e seus autores sejam adequadamente referenciados.

\section{LESTU PUBLISHING COMPANY}

Editora, Gráfica e Consultoria Ltda Avenida Paulista, 2300, andar Pilotis Bela Vista, São Paulo, 01310-300, editora@lestu.org www.lestu.com.br (11) 97415.4679 magens da obra: Canva (Creative Commons)

\section{cccreative}

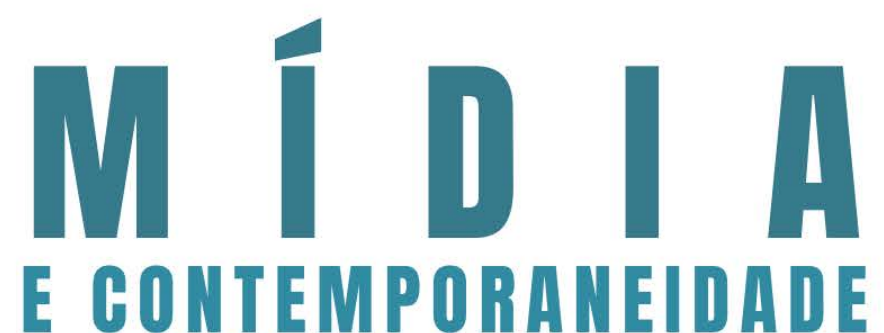

Commons 4.0 https://creativecommons.org/licenses/by/4.0/deed.pt_BR 


\title{
O jornal Flâmula e a formação do "laço social" através da imprensa estudantil em Picos (PI)
}

\author{
Jailson Dias de Oliveira e Nilsângela Cardoso de Lima
}

\section{INTRODUÇÃO}

Ao evidenciar fatos que despertam o interesse das pessoas, os meios de comunicação também desempenham o papel de integradores, pois contribuem para a formação de um sentimento de ligação entre os cidadãos. Os discursos emanados através da imprensa, e seus efeitos de verdade, fortalecem os vínculos e o estímulo do debate público. Assim, os diversos meios, TV, rádio, impresso, internet, são indispensáveis para uma sociedade que se mostra cada vez mais complexa e multifacetada, com grupos distintos que muitas vezes tendem a caminhar em direções opostas. 
A imprensa produzida em cada época deve ser estudada para compreender o período no qual circulou e os discursos que através dela foram veiculados, além da sociedade na qual estava inserida. Logo, o jornalismo contribui não apenas para a integração entre as instituições e as pessoas, mas também entre a própria sociedade, formando laços, proporcionando um sentimento de unidade, ou seja, um laço social (WOLTON, 1996).

Segundo Wolton (1996), os meios de comunicação de massa possibilitam uma espécie de laço invisível entre os sujeitos à medida que eles consomem os mesmos conteúdos. Fazendo uma análise mais específica sobre a televisão, o autor explica que o telespectador, ao ver um programa, não se encontra sozinho, pois em outro local há também outra pessoa assistindo ao mesmo tempo o mesmo programa, o que configura uma recepção simultânea. Com isso, o autor sugere que a televisão, mesmo quando consumida de forma particularizada, agrega os sujeitos e lhes oferece "a possibilidade de participar individualmente de uma atividade coletiva" (ibid., p. 15).

O pensamento de Wolton (1996), por sua vez, pode contribuir para refletir outros meios de comunicação além da televisão, considerando que não são apenas os meios eletrônicos que podem ser utilizados como elemento de integração, o mesmo é válido para o jornal impresso, a primeira mídia generalista surgida no mundo (LAGE, 1987).

As páginas de um periódico podem ser empregadas para gerar o sentimento de pertencimento, uma vez que são registrados acontecimentos e opiniões com potencial de atrair a atenção da coletividade. Dessa forma, parte-se do conceito de laço social, proposto pelo sociólogo francês Wolton (1996; 2012), por considerar que o jornal estudantil Flâmula, através da produção e veiculação de notí- cias, promove o sentimento de pertencimento entre os leitores que consomem as mesmas ideias e informações políticas, sociais, culturais, econômicas etc.

Nesse sentido, a problemática da pesquisa gira em torno do questionamento do papel social que o jornal Flâmula exerceu junto aos leitores, na medida em que colocava em destaque assuntos que consideravam de interesse coletivo, bem como compartilhavam ideias e informações pautando o debate público. Com isso, o objetivo é analisar o discurso produzido pelo jornal estudantil Flâmula e sua relação com a sociedade no ano de 1952.

O jornal estudantil Flâmula foi lançado oficialmente em 15 de março de 1952, quando circulou a sua primeira edição. A publicação era impressa pela Gráfica Picoense e produziu um total de quatorze edições, cuja última chegou às mãos dos leitores em 18 de janeiro de 1953. O mesmo era editado por alunos que integravam o Grêmio Estudantil da Costa e Silva e professores do Ginásio Estadual Picoense. Além dos estudantes, professores e diretores, destaca-se que havia a participação de pessoas que não integravam a escola, mas eram convidadas a colaborar: "O jornal era visto como um desdobramento da instalação da escola secundarista em Picos, ocorrida em 09 de março de 1950" (SOUSA, 2019, p. 81).

Deste jornal estudantil, selecionou-se as matérias "Rainha dos Estudantes"; "Serviço Social da Indústria" e "Tiro de Guerra 201. Reservistas de 1951" que foram publicadas em três edições diferentes no ano de 1952 a fim de analisar os discursos produzidos pelos seus colaboradores. Tais matérias tratam sobre acontecimentos que diziam respeito a sociedade picoense chamando a atenção do leitor para temas que fossem de interesse coletivo e social. Dessa forma, a metodologia adotada foi a Análise de Discurso (AD), na 
perspectiva de Foucault (2009; 2019), por entender que todo discurso é controlado, selecionado, organizado e redistribuído por um conjunto de procedimentos que lhe são internos e externos e deve ser analisado de acordo com a época na qual foi produzido. Sendo um jornal produzido no ambiente escolar, nesse caso o Ginásio Estadual Picoense (GEP), recorre-se ainda a Foucault (2009) que considerava a escola como normatizadora de indivíduos, na medida em que orientava os estudantes para o papel a ser exercido na sociedade.

\section{LAÇO SOCIAL E JORNAL ESTUDANTIL FLÂMULA}

Wolton (2012) salienta que as mídias generalistas são fundamentais para a democracia. O autor é um defensor de que o espectador das mídias não é um ser passivo de manipulação, mas é capaz de formar o seu próprio senso crítico, contribuindo assim para responder aos detratores de veículos como a TV:

Não há democracia possível, então, sem mídias generalistas que privilegiem a lógica da oferta a mais ampla possível, mesmo que, simultaneamente, a segmentação dos mercados da oferta e da demanda prova a vitalidade das mídias temáticas. É preciso admitir esse duplo paradoxo: não há uma cultura de massa sem uma oferta generalista a mais ampla possível, mas essa oferta, ao mesmo tempo que é muito difícil de recomeçar, suscita pouca consideração e reconhecimento da parte de quase todos os públicos, que serão sempre mais atentos à oferta temática, contudo, mais fácil de organizar. (WOLTON, 2012, p. 67-68).

Pela perspectiva do Wolton (2012), as mídias generalistas são fortalecedoras de um regime em que as pessoas tenham o direito de participar e nisso se enquadram os jornais impressos. Dessa for- ma, entende-se que o jornal Flâmula contribuiu para que os leitores alimentassem o sentimento de pertencimento no Município de $\mathrm{Pi}$ cos, uma vez que tratava de temáticas abrangentes relacionadas ao cotidiano da sociedade, como pode ser conferido ao longo de suas páginas.

Wolton (1996) explica que a noção de laço social vai além daquilo que realmente se pode conceber inicialmente. Não é apenas uma religião, ou o poder público que pode gerir nas pessoas essa ideia de solidariedade e até defesa de ideais comuns, mas também a imprensa. Ao terem acesso a determinado conteúdo através das páginas dos jornais, os leitores formarão a própria opinião e deverão compartilhá-la entre si, estabelecendo um debate sobre questões que lhes são de interesse:

A noção de laço social é, talvez, uma das mais complicadas das ciências sociais, porque ela vai desaparecendo à medida que nos aproximamos dela. Formulada por Durkheim e pela escola francesa de sociologia numa perspectiva mais institucional do que cultural - com uma destacada interpretação do papel da religião como laço social - ela foi, em seguida, utilizada e ampliada pela antropologia e pela antropologia cultural. Como se fosse mais fácil destacar as características de laço social nas outras sociedades do que na nossa. O crescimento das instituições sociais, depois a multiplicação das políticas, cobrindo progressivamente todos os setores da sociedade (trabalho, educação, família, saúde, transportes...) deram a sensação de que o laço social localizava-se, sobretudo nas práticas sociais institucionalizadas. (WOLTON, 1996, p. 123).

O jornal Flâmula pode ser estudado segundo a perspectiva de Wolton (1996), uma vez que o mesmo circulou em uma época 
de proliferação da imprensa estudantil no Brasil, que vai de 1930 a 1960. Essas publicações - embora fossem produzidas nas escolas por alunos, professores e colaboradores externos - não ficavam restritas aos seus muros, ou eram direcionadas apenas à comunidade escolar, mas circulavam pela cidade (LOPES, 2016). O jornal picoense analisado neste trabalho estava dentro das características da imprensa do período. Nas páginas dos periódicos brasileiros e piauienses podiam ser encontradas publicações que tratavam sobre acontecimentos gerais relacionados à vida da sociedade picoense, e não apenas à cultura escolar.

Como a imprensa periódica, o jornal e a revista escolares são fontes importantes para a compreensão do funcionamento pedagógico da escola, de seu ideal educativo e do que desejava projetar de si. Muitas vezes, para além da escola, funcionavam como periódicos da localidade onde a escola situava-se. (LOPES, 2016, p. 97).

Assim, a imprensa estudantil é uma fonte histórica importante para entender os discursos veiculados em suas páginas pelas pessoas que produziam as publicações. A visão construída por este tipo de imprensa sobre a sociedade revela o contexto histórico em que estava inserida e interessa como forma de compreensão da produção intelectual da época. Segundo Amaral (2013, p. 123), "nos estudos históricos que privilegiam a investigação das práticas culturais, seus sujeitos e sua produção, os jornais estudantis são considerados elementos potenciais para a apreensão dos discursos e do cotidiano escolar".

Os jornais estudantis que circulavam no Brasil e no Piauí nos anos 1950, mencionando-se aqui o Flâmula, possuíam em sua cons- tituição artigos de opinião sobre fatores que iam desde as questões locais até assuntos voltados para a cultura, como a análise de livros e filmes. Pode-se entender a continuidade da imprensa literária praticada no Piauí no século XIX, quando foram registrados periódicos em escolas de Teresina.

Ao lado do jornalismo literário e político, podemos assinalar o surgimento do jornalismo escolar/educacional no Piauí. Muitos desses jornais escolares/estudantis surgiam apresentando em seu cabeçalho o nome "literário", o que demons tra a relação que coexistia na imprensa entre jornalistas, literatos, políticos, professores, estudantes, isto é, homens que dominavam a escrita. Para tratar sobre o assunto, selecionou-se o jornal A Mocidade Piauhyense [...] (LIMA; SOBRINHO, 2020, p. 233).

Casassanta (1939 apud AMARAL, 2013) salienta que os jornais escolares não apenas desempenhavam o papel de união de uma localidade, mas integravam a escola com a comunidade, pois divulgavam as ações dos estudantes e realizações do colégio, dando-lhes publicidade. Além disso, garantiam que houvesse o espírito de iniciativa e união entre os alunos:

A publicidade é um meio de êxito e sucesso. O jornal escolar pode manter vivas as atividades, incentivando o entusiasmo entre os alunos, levando-os a empregar nelas todo o esforço e toda a atenção. $O$ jornal une a escola à sociedade, pondo-a constantemente a par de sua vida e de suas realizações. Estabelece, assim, um entendimento recíproco, interessando o povo na obra escolar. (CASASSANTA, 1939 apud AMARAL, 2013, p. 125). 
A respeito do Flâmula, Lopes (2016) salienta o bom estado de conservação dos exemplares do periódico e a peculiaridade do mesmo já nascer com uma gráfica própria que imprimiria as suas edições. Há ainda outras particularidades desse jornal como o espaço dado à administração do Município. Ainda de acordo com o autor, "específico desse periódico era a publicação de leis municipais, o que parece ser um elemento que marca o desejo desses periódicos atingirem um público leitor mais amplo do que aqueles diretamente ligados à instituição escolar" (LOPES, 2016, p. 103).

O desejo de chegar a um maior número de leitores, conforme apontado por Lopes (2016) mostra que o jornal já era produzido com essa intenção, colocando-se à disposição do Município de Picos. Em suas páginas também podem ser observadas publicidades de estabelecimentos comerciais. O jornal ainda cobrava $\mathrm{Cr} \$ 1,00$ por edição, como forma de financiamento. A venda de exemplares, no entanto, não era uma peculiaridade do Flâmula, mas estava presente em outros folhetins brasileiros da época.

\section{DISCURSO JORNALÍSTICO DE FLÂMULA: ENTRE NORMAS E VONTADE DE VERDADE}

Para este estudo, optou-se pela metodologia da Análise do Discurso em Foucault (2009; 2019), destacando o papel de quem escreve e reproduz a sua visão sobre a realidade. Nesse caso específico, há a produção de saberes por meio daqueles que viviam a escola, um centro normatizador do indivíduo, que o disciplina para o convívio em sociedade e a vontade de verdade sobre aquilo que é produzido:

Ora, essa vontade de verdade, como os outros sistemas de exclusão, apoia-se sobre um suporte institucional; é ao mesmo tempo reforçada e reconduzida por todo um compacto conjunto de práticas como a pedagogia, é claro, como o sistema dos livros, da edição, das bibliotecas, como as sociedades de sábios outrora, os laboratórios de hoje. (FOUCAULT, 2009, p. 17).

Vale-se da possibilidade de usar a palavra e emitir enunciados como um sinal de credibilidade, diferenciando-se assim daqueles que são interditados pela sociedade. Foucault (2009) destaca que desde a Idade Média é a palavra que interdita o louco, aquele que é desprovido de razão. Se a alguém é dada a possibilidade de se manifestar e emitir os seus enunciados, como em um jornal impresso, é porque essa pessoa é reconhecida como detentora de credibilidade.

A sua produção chega até as demais que a debatem, acreditando na mesma ou não, uma vez que cada discurso é produzido com a perspectiva de emitir a verdade compreendida pelo autor:

Ora, creio que o problema não é de se fazer a partilha entre o que num discurso revela da cientificidade e da verdade e o que revelaria de outra coisa; mas de ver historicamente como se produzem efeitos de verdade no interior de discursos que não são em si nem verdadeiros nem falsos. Segundo inconveniente: refere-se necessariamente a alguma coisa como o sujeito. (FOUCAULT, 2019, p. 44).

Amparado na perspectiva de análise discursiva das produções do Flâmula, na perspectiva de Foucault (2009; 2019), e tendo como base o conceito de laço social proposto por Wolton (1996), analisa-se no tópico abaixo três matérias publicadas em três edições diferentes, todas na primeira página do jornal e sem assinatura. 
A primeira é intitulada "Rainha dos Estudantes"1, que circulou na primeira edição do jornal, em 15 de março de 1952, e trata sobre a mobilização da sociedade para angariar recursos através do evento que escolheria uma estudante para receber o título e, assim, conseguir lançar o jornal. A segunda refere-se à matéria "Tiro de Guerra 201. Reservistas de 1951"2, que circulou na segunda edição de 29 de março de 1952, e discorre sobre o juramento à bandeira nacional realizado pela turma de 1932 na praça central da cidade. Não há o nome da praça, mas entende-se que se trata da Félix Pacheco. Já a terceira matéria, "Serviço Social da Indústria (SESI)" ${ }^{3}$, foi publicado na terceira edição, lançada em 12 de abril de 1952, e aborda a luta para a instalação de uma agência do SESI em Picos. Através delas, compreende-se a ideia de laço social por meio do discurso jornalístico sobre acontecimentos verificados em Picos que iam bem além da cultura escolar, pois tratavam sobre temas que envolviam a sociedade de um modo geral.

\section{O JORNAL FLÂMULA E A FORMAÇÃO DO “LAÇO SOCIAL" ATRAVÉS DA IMPRENSA ESTUDANTIL EM PICOS (PI)}

O Flâmula circulou entre os anos 1952 e 1953, produzido pelo Grêmio Estudantil da Costa e Silva, de dentro do Ginásio Estadual Picoense. Compreende-se que o mesmo não se detinha apenas na divulgação da cultura escolar. A leitura dos seus arquivos permite observar a variedade de assuntos abordados, destacando-se os acontecimentos sociais (SOUSA, 2019). É devido a essa publicação de fatos que atraiam a atenção da população que o periódico merece a análise segundo a perspectiva do sociólogo francês Wolton (1996), a

\footnotetext{
RAINHA (1952)

2 TIRO (1952)

3 SERVIÇO (1952).
}

partir da concepção de laço social.

Pode ser percebido um laço estabelecido dentro da sociedade picoense, segundo o discurso irradiado por meio do jornal, no texto "Rainha dos Estudantes", que circulou na primeira edição do jornal. Apesar de o título transmitir a ideia inicial de que o texto discorreria sobre um concurso de beleza feminina, destacando as duas candidatas que participaram: Idelzuite Leal e Maria do Carmo Cardoso, não é o que se verifica. Nem os aspectos físicos das candidatas, nem o evento em si foram ressaltados na redação, mas a mobilização promovida pelos estudantes em busca de uma finalidade maior, algo que pode ser percebido logo no primeiro parágrafo da matéria:

No segundo semestre do ano letivo findo, resolveram os corpos docentes e discentes do Ginásio, integrado o segundo pelo Grêmio Literário Da Costa e Silva, levar a efeito uma campanha para levantar recursos financeiros capazes de facultar ao Grêmio a aquisição de uma tipografia, que ensejasse o tão sonhado jornal dos estudantes. (RAINHA, 1952, p. 1).

Através da publicação percebe-se o interesse da redação do órgão Flâmula em mostrar o empenho dos professores e estudantes para constituir a gráfica e lançar o jornal. Há, assim, uma ênfase no empenho da comunidade escolar de dispor de um periódico através do qual os bens simbólicos seriam projetados para a coletividade. Por se tratar de um "sonho", conforme dito no texto, havia o entendimento do periódico como algo que fortaleceria a ligação entre escola e sociedade. Isso vai de encontro ao que é salientado por Casassanta (1939 apud AMARAL, 2013) quando trata da integração da escola com a comunidade onde a mesma se encontrava.

O terceiro parágrafo da matéria apresenta os resultados al- 
cançados pelos estudantes na sua campanha de angariar recursos para aquisição da tipografia:

E não se sabe o que mais merece ser louvado, se o entusiasmo e a cordialidade com que se lançaram à empresa os jovens estudantes, ou a imparcialidade com que os orientou seu dedicado mentor. E assim foi que o êxito do gentilíssimo prélio superou as estimativas mais otimistas, apesar de já tão conhecida a liberalidade com que o povo de Picos coopera monetariamente para todas as causas de elevada finalidade. (RAINHA, 1952, p. 1).

O discurso apresentado no texto mostra uma sociedade picoense desprendida, que entendeu a importância da iniciativa da comunidade escolar e colaborou financeiramente. Haveria também por esse aspecto a compreensão por parte da população de que o jornal significaria um bem maior para a coletividade, um desdobramento da implantação do Ginásio Escolar Picoense em Picos. Fato que se deu após muita luta (SOUSA, 2005).

É importante se valer de Wolton (1996) ao destacar o papel das publicações impressas como divulgadoras de acontecimentos dentro da sociedade. Por ser o jornal impresso uma fonte de referência, é possível entender porque o mesmo é capaz de promover a ideia de laço social. $O$ discurso através das palavras escritas interessa diretamente aquele grupo de pessoas que o lê e o interpreta. “Na imprensa escrita, a publicação que, sem dúvida, mais se relaciona com essa função de laço, de espelho e de memória é a dos semanários de informação e de fotos que existem em todos os países e dos quais Life e Paris-Match talvez sejam melhores exemplos" (ibid., p. 124).

Mesmo que Wolton (1996) utilize como exemplo impressos estrangeiros, as suas palavras levam a conclusão da sua consideração quanto à importância das páginas impressas. A constituição de um jornal para a época em que o periódico estudantil circulou na cidade de Picos, início dos anos 1950, era importante para o fortalecimento dos laços entre a sociedade e para que se desse a ideia de desenvolvimento, uma vez que os estudantes teriam algo onde poderiam imprimir as suas ideias e pensamentos, bem como registrar acontecimentos escolares e sociais.

Apesar de a expressão rede social ser associada hoje a internet e as suas inúmeras possibilidades, esse conceito é mais antigo e não se refere apenas ao mundo virtual. $O$ discurso adotado no texto "Rainha dos Estudantes", com ênfase no apoio e colaboração financeira da sociedade, mostra a existência de conexão entre as pessoas. Havia uma rede, conforme apresentado no jornal, que permitiu a cooperação em favor de um mesmo objetivo que movimentou a sociedade daquela época.

Castells (2016) conceitua redes e sua dinamicidade no seio da sociedade:

Redes são estruturas abertas capazes de expandir de forma ilimitada, integrando novos nós desde que consigam comunicar-se dentro da rede, ou seja, desde que compartilhem os mesmos códigos de comunicação (por exemplo, valores ou objetivos de desempenho). Uma estrutura social com base em redes é um sistema aberto altamente dinâmico suscetível de inovação sem ameaça ao seu equilíbrio. (CASTELLS, 2016, p. 554).

Portanto, a primeira edição do Flâmula transmite a ideia de que a cidade de Picos do início dos anos 1950 partilhou naquele momento ideais semelhantes quanto a educação e os seus desdobramentos políticos, culturais e sociais esperados para o desenvolvimento da juventude picoense por meio da instrução secundária. 
O objetivo que fica claro desde o lançamento da primeira edição, quando o jornal coloca em destaque a criação e circulação da folha, é resultado dos "verdadeiros amigos da instrução" (Figura 1), tanto do povo picoense como de outros municípios, que viam a educação como uma possibilidade para o progresso material e espiritual da sociedade.

Figura 1 - Primeira edição do Flâmula- 15 de março de 1952

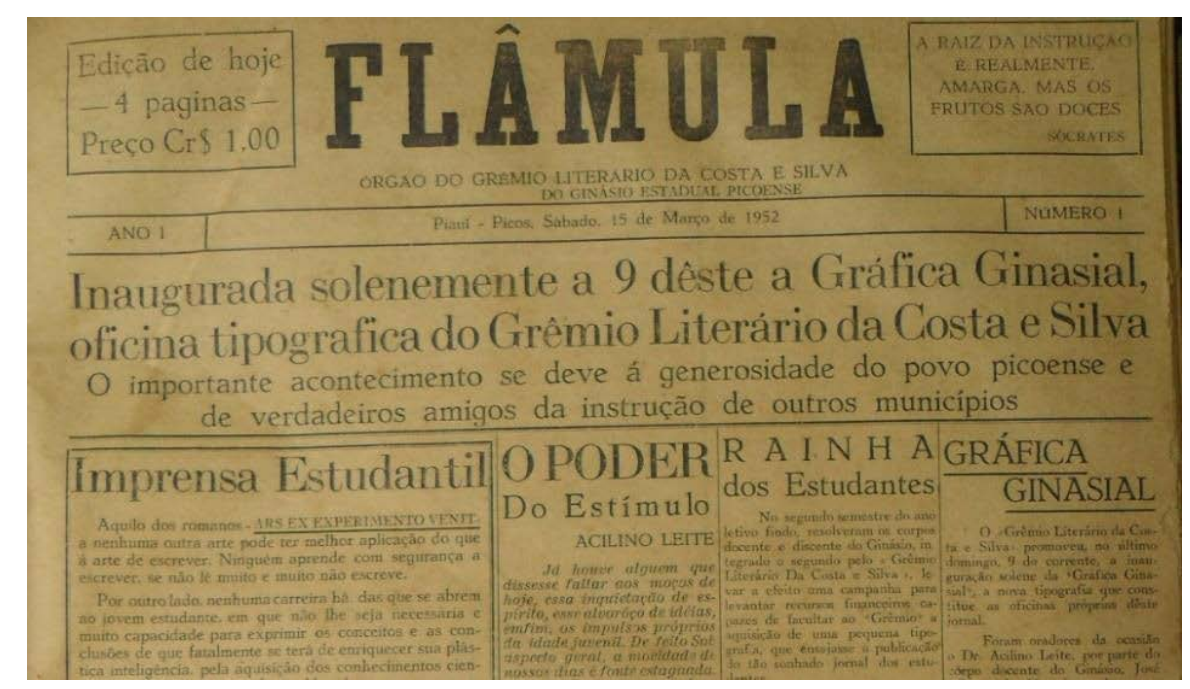

Fonte: MUSEU (2022)

O segundo texto selecionado para a análise deste trabalho é o já mencionado "Tiro de Guerra 201. Reservistas de 1951". Essa matéria circulou na segunda edição do Flâmula, lançada em 29 de março de 1952, e narra a solenidade de juramento à bandeira do Brasil pelos jovens em idade de alistamento militar. O "Tiro de Guerra" era uma organização do Exército brasileiro que existia em Picos, antes da instalação do $3^{\circ}$ Batalhão de Engenharia e Construção $\left(3^{\circ}\right.$ $\mathrm{BEC})$, em 1971. Até aquele momento, ele se constituía no principal representante das Forças Armadas na cidade e era onde os jovens que completavam 18 anos prestavam o serviço militar obrigatório.

As palavras contidas na publicação, carregadas de deferências às autoridades, militares e estudantes, levam a entender que o evento era de grande importância para os munícipes, pois acontecia no centro da cidade de Picos. $O$ texto ressalta o aspecto de união e de movimentação, como pode ser percebido no primeiro parágrafo: "Foi um acontecimento de rara repercussão na vida social e cívica desta cidade, a cerimônia do juramento à Bandeira, pela turma de reservistas do Tiro de Guerra 201, classe de 1932, o que se verificou na praça principal de Picos, na tarde de 21 do corrente" (TIRO, 1952, p.1).

Na sequência da publicação, há a listagem de alguns dos nomes que se fizeram presentes, bem como a participação popular.

A solenidade contou com a presença das autoridades locais, estudantes, e grande massa popular, desenvolvendo-se ao som de vibrantes marchas militares, pela Banda Municipal, sob a presidência do tenente Joaquim Cipriano de Sousa, disciplinado e culto oficial do exército, que também presidiu a comissão examinadora, designada pelo Sr. General Comandante da $10^{\circ}$ Região para apurar o grau de aproveitamento dos jovens candidatos à reserva de segunda linha. (TIRO, 1952).

Ao final da coluna, há a divulgação do resultado com o nome do melhor colocado na turma que fazia o juramento à bandeira.

Nas provas a que se submeteram os jovens alunos da escola de guerra picoense, obteve o primeiro lugar o ginasiano Mário Marreiros de Araújo, um dos estudantes que mais vem aproveitando nas lições 
de nosso educandário e um dos mais dedicados e úteis membros do Grêmio Literário Da Costa e Silva, o que sobremodo nos desvanece. (TIRO, 1952).

Como se pode entender, a matéria enaltece não apenas o estudante Mário Marreiros de Araújo, mas o fato de o mesmo ser aluno do Ginásio Estadual Picoense e fazer parte do grêmio que produzia o Flâmula. Através desse discurso valoriza-se o papel da escola e da associação estudantil como úteis para a cidade. Ou seja, a redação produz um discurso que contribuiria para reforçar a ideia de que a implantação da escola secundarista foi muito importante para o desenvolvimento material e cultural de Picos, tendo como resultado a formação de alunos disciplinados e aptos ao trabalho.

O destaque dado pelo jornal ao estudante Mário Marreiros de Araújo e o papel desempenhado por ele dentro da sociedade picoense, remetem ao entendimento de Foucault (2009) sobre a escola como um centro produtor de saberes, que resulta na manifestação de poder. Esse poder, segundo o filósofo, não se tratava da capacidade de destruir, mas de projetar o indivíduo conforme a sociedade espera. A matéria do Flâmula evidencia essa satisfação. Um jovem deixou uma instituição de normas, a escola, para participar de outra onde há rigor e exigência de disciplina, o Exército. O poder circula pela sociedade, não estando presente apenas de cima para baixo, mas entre as pessoas e as instituições que o exercem (FOUCAULT, 2019).

O laço social, na perspectiva de Wolton (1996), também pode ser compreendido na notícia "Tiro de Guerra 201. Reservistas de 1951", tanto pela descrição do evento nas páginas no jornal, como pela citação indireta da relevância da escola para a população. Isso permitiria mais uma vez que os cidadãos se sentissem ligados a algo em comum. O desempenho dos estudantes mostraria como a escola fundada em 1950 vinha sendo útil para a cidade. O terceiro e último texto escolhido para análise, "Serviço Social da Indústria (SESI)", foi publicado na 3a edição, lançada em 12 de abril de
1952. Destaca-se que tanto esse quanto os anteriores estão na primeira página do periódico, onde começam e terminam. A matéria trata sobre a necessidade da instalação de uma agência do SESI em Picos, com o fim de capacitar a população, ao passo em que enaltece o papel da instituição de ensino técnico para o Brasil. O primeiro parágrafo discorre sobre a luta que já perdura desde o ano anterior à fundação do jornal, bem como as possibilidades de obter sucesso.

Desde o meado de 1951 que o Juiz de Direito da Comarca vem levantando a estatística dos industriários do município de Picos, afim de fazer um apelo às autoridades competentes, para a criação de uma agência do SESI nesta cidade. E há grandes e fundadas esperanças de que a medida se concretizará, uma vez que um dos elementos de mais destaque da importantíssima organização presidida pelo $\mathrm{Dr}$. Euvaldo Lodi é um dos filhos de Picos que mais elevam lá fora o nome da terra natal e que mais seguras demonstrações vem dando de que não se esquece de seu povo, particularmente de sua mocidade e de seus trabalhadores. (SERVIÇO, 1952).

Segundo o Flâmula, há um grande interesse por parte do juiz em instalar a agência do SESI em Picos, embora o nome dele não seja evidenciando nesse trecho. Ao citar o trabalho do magistrado, o periódico afirma que o mesmo demonstra interesse pelo desenvolvimento educacional da cidade. Nota-se ainda o papel desempenhado pelo integrante do Poder Judiciário, atuando como uma liderança política, uma vez que buscava benefícios para o Município. A expectativa positiva de que a referida agência se instale na cidade está amparada no fato de um picoense integrar a direção do SESI.

O jornal mostra através do seu discurso o protagonismo desempenhado pelas autoridades constituídas em ser fomentadoras do 
desenvolvimento local. Salienta-se que a atuação dos magistrados, indo além de funções jurídicas, parecia comum na época, pois o Ginásio Estadual Picoense se tornou possível devido ao papel do juiz Vidal de Freitas (SOUSA, 2005).

O segundo parágrafo da matéria segue com o enaltecimento da figura do juiz e as conquistas já concretizadas em favor da população.

É desnecessário frisar, que se trata do Dr. Helvídio Martins Maia, Diretor da Divisão de Delegacias Regionais do SESI. Agora mesmo S. Excia., que quando de sua estadia entre nós, no mês passado, fundara no Instituto Monsenhor Hipólito o curso Morvan de Figueiredo, com o fornecimento de máquinas de costura, material e verba para manutenção de aulas técnicas a moças pobres, acaba de conseguir mais do Serviço Social da Industria, que tantos serviços sociais vem prestando ao povo em todo o Brasil [...] (SERVIÇO, 1952).

Portanto, segundo o jornal, a atuação do juiz junto ao SESI já vinha acontecendo através de realizações implementadas em Picos. Tais projetos cotados para a cidade não aconteciam por acaso. Em 1952, segundo o jornal, Picos era o segundo município mais populoso do interior do Piauí com 55.120 habitantes, como é destacado na chamada de capa da terceira edição do Flâmula (Figura 2).

Assim, o trabalho dessa autoridade é evidenciado, mostrando-a como um trabalhador incansável em favor do Município que, na década de 1950 , possuía apenas $26 \%$ da população com mais de 10 anos alfabetizada, e o ensino secundário, até a chegada do Ginásio Estadual Picoense, era inacessível para a maioria pelo fato de na cidade não ter nenhum ginásio, de acordo com Sousa (2005). O periódico projeta o Juiz de Direito da Comarca como alguém de atuação fundamental, o que exigiria as deferências tendo em vista o cargo que ocupava.
Figura 2- Terceira edição do Flâmula - 12 de abril de 1952

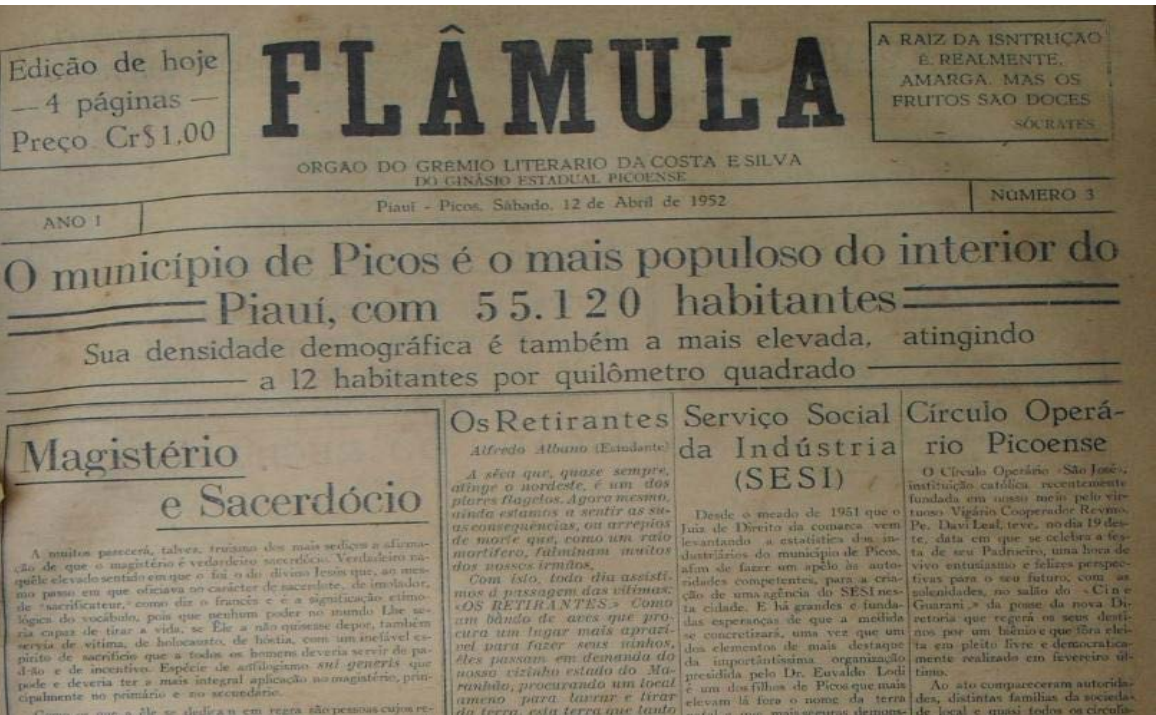

Fonte: MUSEU (2022)

É importante mais uma vez destacar que as temáticas abordadas para análise tratavam sobre acontecimentos que mobilizaram a sociedade, sobretudo na constituição da gráfica para que o Flâmula pudesse ser impresso. Logo, o jornal Flâmula abrigava em suas páginas não só matérias que refletiam sobre o problema da educação do Piauí, mas abria espaço para a publicação de leis municipais e assuntos ligados à vida política, economia, cultura e sociedade.

De acordo com Lopes (2016), apesar de o Flâmula ser definido como um jornal estudantil, nota-se que a direção quis ampliar seu público leitor para além dos sujeitos vinculados à escola. Ação que pode ser identificada tanto em termos de conteúdo, que não se restringia a vida escolar do Ginásio Estadual Picoense, como também na admissão de textos de outras pessoas que não fossem alunos, professores e/ou inspetores. 


\section{CONSIDERAÇÕES FINAIS}

O presente estudo abordou o jornal estudantil Flâmula a partir do conceito de "laço social" em Wolton (1996), buscando analisar os discursos reproduzidos pela publicação sobre acontecimentos sociais que estavam além dos muros do Ginásio Estadual Picoense onde o mesmo era publicado. O periódico, seguindo um padrão comum à imprensa estudantil da época, tratava sobre temas bem gerais, interessando a um número maior de leitores do que a comunidade escolar. Ele discorria sobre as práticas pedagógicas e cultura escolar, mas os seus colaboradores demonstravam interesse pelos acontecimentos mais gerais da cidade de Picos.

Através das matérias selecionadas para o estudo, abordou-se o conceito laço social de Wolton (1996), pois em publicações como a intitulada "Rainha dos Estudantes", há o discurso de união, uma vez que o periódico salienta a colaboração financeira da sociedade para que a gráfica fosse adquirida e o jornal pudesse ser publicado. Haveria aí também o espírito de irmandade entre os moradores locais, constituindo uma rede, conforme preconizado por Castells (2013). A população teria compreendido a importância de a escola dispor de um jornal e garantiu que os estudantes dispusessem dos recursos que necessitavam. As palavras utilizadas na publicação estão repletas de elogios à atuação dos picoenses, procurando evidenciar esse espírito de caridade que os caracterizaria.

O jornal Flâmula, um periódico típico dos anos 1950, se mostra uma fonte valiosa para pesquisas, pois a boa conservação das suas edições (LOPES, 2016), permite a análise aprofundada da cultura escolar do Ginásio Estadual Picoense, bem como da cidade onde a mesma estava inserida. Isso mostra como os jornais estudantis são fontes que devem ser consultadas para pesquisas mais abrangentes, uma vez que funcionavam como um elemento de ligação entre a população, tratando sobre temáticas bem amplas

\section{REFERÊNCIAS}

AMARAL, G. L. Os jornais estudantis Ecos Gonzagueanos e Estudante: apontamentos sobre o ensino secundário católico e laico (Pelotas/ RS, 1930-1960). História da Educação, Porto Alegre, v. 17, n. 40, p. 121-142, mai./jul. 2013. Disponível em: https://seer.ufrgs.br/asphe/ article/view/38090. Acesso em: 15 out. 2021.

CASTELLS, M. A sociedade em rede. Trad. Roneide Venâncio Majer. 17. ed. São Paulo: Paz e Terra, 2016.

FOUCAULT, M. A ordem do discurso. Trad. Laura Fraga de Almeida Sampaio. 19. ed. São Paulo: Loyola, 2009.

FOUCAULT, M. Microfísica do poder. 10. ed. Rio de Janeiro: São Paulo: Loyola, 2019.

LAGE, N. Estrutura da notícia. 2. ed. São Paulo: Ática, 1987.

LIMA, N. C.; SOBRINHO, F. S. O. A. A mocidade piauhyense e cultura escolar no Piauí do século XIX. In: LIMA, Nilsângela Cardoso. Páginas da história do Piauí. Teresina: EDUFPI, 2020.

LOPES, A. de P. C. O jornal e a revista escolar: seu lugar nos projetos educativos das escolas e sua importância para a escrita da história das instituições escolares. In: LOPES, A. P. C. (Org.). História de instituições escolares: sujeitos, práticas educacionais e cultura material. Teresina: EDUFPI, 2016, p. 95-105.

MUSEU Ozildo Albano. Acervo. 2022. Disponível em: https://www. museuozildoalbano.com.br/acervo. Acesso em: 14 out. 2021. 
SOUSA, H. C. Um ginásio para a mocidade picoense: cultura escolar de uma instituição de ensino secundário (1950-1971). Orientador: Prof. Dr. Antonio de Pádua Carvalho Lopes. 2019. 395f. Dissertação (Mestrado em Educação) - Centro de Ciências da Educação, Universidade Federal do Piauí, Teresina, 2019. Disponível em: http://www. dominiopublico.gov.br/pesquisa/DetalheObraForm.do?select_action=\&co_obra=177042. Acesso em: 15 out. 2021.

SOUSA, J. B. Picos e a consolidação de sua rede escolar: do grupo escolar ao ginásio estadual. Orientador: Prof. Dr. Antonio de Pádua Carvalho Lopes. 2005, 161f. Dissertação (Mestrado em Educação) - Centro de Ciências da Educação, Universidade Federal do Piauí, Teresina, 2005. Disponível em: https://www.livrosgratis.com.br/ler-livro-online-134645/picos-e-a-consolidacao-de-sua-rede-escolar--do-grupo-escolar-ao-ginasio-estadual. Acesso em: 15 out. 2021.

SERVIÇO Social da Indústria (SESI). Flâmula. Picos, ano I, n. 3, p. 1, 12 abr. 1952

RAINHA dos estudantes. Flâmula. Picos, ano I, n. 1, p. 1, 15 mar. 1952.

TIRO de guerra 201. Reservistas de 1951. Flâmula. Picos, ano I, n. 2, p. 1, 29. 1952.

WOLTON, D. Elogio do grande público: uma teoria crítica da televisão. Trad. José Rubens Siqueira. Editora Ática: São Paulo, 1996.

WOLTON, D. Internet, e depois? Uma teoria crítica das novas mídias. Trad. Isabel Crossetti. 3. ed. Porto Alegre: Sulina, 2012.

\section{Autoria}

Jailson Dias de Oliveira

Mestrando do Programa de Pós-Graduação em Comunicação da UFPI, Professor da Faculdade R. Sá. E-mail: jailsondias2@hotmail. com. ORCID: 0000-0002-6184-2856.

\section{Nilsângela Cardoso de Lima}

Doutora. Professora do Programa de Pós-Graduação em Comunicação da UFPI e do Curso de Comunicação Social da UFPI. E-mail: nilsangelacardoso@ufpi.edu.br. ORCID: 0000-0001-9858-3838. 